\title{
Dimensões da inovação na Pós-Graduação: papéis e significados
}

\section{Dimensions of innovation in Post-Graduation: roles and meanings}

\author{
CRISTIANE SANTANA TELES PEREIRA* \\ ALMIR MARTINS VIEIRA** \\ WANDERSON DA SILVA DAMIÃO***
}

\section{RESUMO}

Este trabalho tem por objetivo identificar o papel da inovação na visão dos gestores dos programas de pós-graduação das instituições de ensino localizadas na região do $A B C$ paulista. $O$ campo conceitual versa a respeito da pós-graduação no Brasil e acerca da inovação como tema presente nesse cenário. À luz do que preconiza o Manual de Oslo, assume-se que os conceitos referentes à educação e à inovação devem ser construídos numa perspectiva integrada, tanto para o desenvolvimento das empresas quanto das instituições de ensino. Por meio de uma abordagem qualitativa, os dados foram coletados com a realização de entrevistas ancoradas em roteiro semiestruturado. Participaram da pesquisa seis gestores dos programas de pósgraduação das seguintes instituições: Centro Universitário da FEI (Administração); Universidade Metodista de São Paulo - UMESP (Administração e Comunicação); Universidade Municipal de São Caetano do Sul - USCS (Administração); e Universidade Federal

* Universidade Metodista de São Paulo. Mestre em Administração (2016) pela Universidade Metodista de São Paulo (UMESP). crissteles@gmail.com .

** Almir Martins Vieira. Universidade Metodista de São Paulo. Doutor em Educação pela UNESP (2007); mestre e graduado em Administração pela Universidade Metodista de São Paulo (2001). almir.vieira@gmail.com .

*** Doutorando em Administração de Empresas pela Universidade Metodista de Piracicaba (UNIMEP). Mestre em Administração (2014) pela Universidade Metodista de São Paulo (UMESP). wandersoniprm@hotmail.com . 
do ABC - UFABC (Políticas Públicas e Planejamento e Gestão de Território). A análise foi feita com base em duas categorias definidas a priori: "posição temática da inovação na pós-graduação"; e "colaboração entre governo, empresas e instituições de ensino". Os resultados apontaram que o papel da inovação deve ir além de uma disciplina isolada, integrando-se com todas as demais, além de fazer parte de toda a estrutura dos programas de pós-graduação, contemplando todas as ações de pesquisa.

Palavras-chave: Inovação e Pós-Graduação. Educação. Pesquisa.

\section{Abstract}

This research aimed to identify the role of innovation for managers of Postgraduate Programs in Applied Social Sciences of universities located in $A B C$ paulista. It presents theoretical aspects related to innovation and post-graduation, considering Brazilian higher education scenario. Through a qualitative approach, the data have been gained using semi-structured individual in-depth interviews. Six managers/professors of the following postgraduate programs were interviewed: FEI University Center (Administration Course); Methodist University of São Paulo - UMESP (Administration and Communication courses); Municipal University of São Caetano do Sul - USCS (Administration course); and Federal University of ABC - UFABC (Public Policy and Territory Planning and Management courses). Two categories were defined a priori: "relation between innovation and post-graduation"; and "collaboration among government, enterprises and higher education institutions". The results of the study showed that the role of innovation should be to go beyond an isolated and exclusive discipline; it must integrate and interact with all other disciplines of stricto sensu courses, regardless of the area of study, besides being part of the postgraduate program structure.

Key-words: Innovation and Post-Graduation. Education. Research.

\section{INTRODUÇÃO}

No debate acadêmico contemporâneo, é muito comum associar educação de qualidade e desenvolvimento econômico, conforme afirmam Pereira, Franco, Santos e Vieira (2015). De acordo com o que se apresenta no Manual de Oslo (2005), são conceitos interligados, 
posto que crescimento econômico e desenvolvimento tecnológico são passos para o mesmo caminho: alcance de desenvolvimento social e intelectual.

A inovação fortalece o desenvolvimento econômico, social e intelectual de uma região, segundo descrito no relatório final da Coordenação de Aperfeiçoamento de Pessoal de Nível Superior (CAPES) sobre o Plano Nacional de Pós-Graduação (PNPG) 2011/2020. O relatório aponta que "o investimento em bens intangíveis, como capital humano, pesquisa científica, desenvolvimento e inovação em produtos e serviços está, reconhecidamente, correlacionado com o alcance de elevados padrões econômicos nacionais"' (BRASIL, 2010, p. 72).

Demo (2002, p. 49) alega que as universidades possuem "papel imprescindível e gerador frente ao desenvolvimento humano" e complementa que são elas que formam as competências e os cidadãos capazes de mudar eticamente a sociedade e a economia, desde que tenham como alavanca um conhecimento inovador. Para Pimenta e Anastasiou (2002, p. 168) a universidade, como instituição social, "se caracteriza como ação e prática social, pautando-se pela ideia de um conhecimento guiado por suas próprias necessidades e por sua própria lógica, tanto no que se refere à descoberta e invenção quanto à transmissão desse conhecimento". Sendo assim, parece possível inferir que o conhecimento esteja contido, de forma sistemática, nas universidades, visto que são espaços voltados à diversidade e à pluralidade de pensamento.

No Brasil, a educação é regida por alguns dispositivos legais que conduzem a relação da academia com a sociedade como o Plano Nacional de Educação (PNE - Lei n. 13.005, de 25 de julho de 2014), a Lei de Diretrizes e Bases (LDB - Lei n. 9.394, de 20 de dezembro de 1996) e o documento específico para a pós-graduação -, o Plano Nacional de Pós-Graduação de 2010 (PNPG), com duração de dez anos, com vigência de 2011 até 2020.

Além dos dispositivos legais, alguns órgãos governamentais tratam especificamente de assuntos relacionados ao ensino no Brasil. No caso da pós-graduação, quem avalia e norteia essa linha de ensino é a CAPES. Em 2010, ela editou o PNPG 2011-2020 e, em 2013, elaborou um relatório final, atrelado ao PNPG (BRASIL, 2010, p. 17), que aponta recomendações para que metas e objetivos sejam 
alcançados. No tocante à inovação, destaca-se, por exemplo, que a pós-graduação tenha foco para contribuir "mais diretamente para a inovação e a formação de recursos humanos para as empresas".

A partir de uma perspectiva de desenvolvimento e crescimento social, intelectual e econômico, como afirmam Etzkowtz e Leydesdorff (2000), a inovação precisa de alguns agentes para acontecer, como o governo, as empresas e as instituições de ensino. Dessa forma, é possível perceber que inovar não é simples, conforme destacam Pinheiro, Santos, Maia e Fernandes (2014, p. 41) quando afirmam que a inovação "é uma atividade de alta complexidade" e que esta necessita de um ambiente "organizacional favorável".

Segundo Etzkowitz e Leydesdorff (2000), conhecimento, política e empresas são elementos impulsionadores da inovação. Essa parceria é chamada de Tríplice Hélice, na qual, de acordo com Cruz, Cruz, Costa e Coronel (2013, p. 8), existe "um novo modelo de interação coparticipativa e interdependente entre as esferas institucionais que se sobrepõem no sentido de assumir uma o papel da outra". Essa relação tem como principal objetivo promover a inovação e o desenvolvimento regional, garantindo prosperidade para a academia, a sociedade, as empresas e o poder público.

O Manual de Oslo (2005) destaca que a inovação tem sido a grande estratégia das organizações para manter suas perspectivas econômicas diante da pressão do mercado. Isso ocorre porque ações inovadoras surgem da criatividade, da competência e da boa vontade de instituições como governo, empresas e universidades em se renovar. Em consonância com o Manual, a CAPES, como órgão avaliador da educação superior brasileira, utilizando o Relatório Final do PNPG (BRASIL, 2010, p. 17), enfatiza a relevância e a necessidade dos estudos em tecnologia e inovação.

Diante desse contexto, este trabalho tem por objetivo identificar o papel da inovação na visão dos gestores dos programas de pós-graduação (stricto sensu), especificamente na área de Ciências Sociais Aplicadas. Os programas elencados para a investigação pertencem à região metropolitana de São Paulo, cuja descrição será detalhada adiante.

Para tanto, o artigo está distribuído em quatro partes, além desta introdução. A primeira parte expõe o campo conceitual, com destaque para os temas da pós-graduação no Brasil e da inovação, 
bem como, a relação desses temas com a educação. Em seguida, os aspectos metodológicos assumidos na pesquisa. A terceira parte mostra os dados coletados e a sua análise, e a última parte traz as considerações finais sobre a investigação realizada.

\section{FUNDAMENTAÇÃo TEÓRICA}

\section{Pós-Graduação no Brasil}

Na perspectiva de Luz e Santos (2007, p. 153), “a geração de conhecimento científico no Brasil equivale a um gradual processo de construção social". No Brasil, a CAPES desempenha papel na expansão e consolidação da pós-graduação stricto sensu (mestrado e doutorado) em todos os Estados da federação, ou seja, apoia a geração que busca o conhecimento científico no Brasil. Afinal, como enfatiza o PNPG (BRASIL, 2010, vol. 1, p. 269), “o pilar básico do desenvolvimento científico e tecnológico de qualquer sociedade está na formação de pesquisadores e cientistas". Em relação a esse propósito, vale destacar parte do documento:

O PNPG 2011-2020, editado pela Coordenação de Aperfeiçoamento de Pessoal de Nível Superior (CAPES), tem como objetivo definir novas diretrizes, estratégias e metas para dar continuidade e avançar nas propostas para a política de pós-graduação e pesquisa no Brasil. Paralelamente a este Plano, elabora-se o novo Plano Nacional de Educação (PNE), em outras instâncias do MEC e de órgãos do governo, exigindo a coordenação de propostas e atividades. De fato, pela primeira vez, um plano nacional de educação contemplará as propostas de diretrizes e políticas do ensino de pós-graduação, isso porque o PNPG será parte integrante do PNE (BRASIL, 2010, p. 2).

Para exercer sua função, a CAPES possui algumas linhas de ação, como avaliação da pós-graduação stricto sensu, acesso e divulgação da produção científica, indução e fomento da formação inicial e continuada de professores para a educação básica (nos formatos presencial e a distância), entre outras.

Com o apoio de fiscalização da CAPES, as universidades elaboram seus currículos para os programas de pós-graduação e 
buscam levar até os alunos conhecimento mais atualizado e composto por estruturas que incluam as novidades do meio acadêmico, mercado e mundo.

No âmbito da educação inovadora, Bryan, Benito e Suarez (2011) verificam a necessidade de realizar mais perspectivas inovadoras e o desenvolvimento sustentável, além, principalmente, de melhorar a gestão dos processos por intermédio de seus gestores e educadores. Afinal, como afirmado por Silva e Bardagi (2015, p. 707), “países com nível alto de desenvolvimento social e econômico preocupam-se com a qualidade dos cursos de pós-graduação e com a escolha do indivíduo quanto à carreira de pesquisador".

O PNPG (BRASIL, 2010, p. 76) identifica a inovação como excelente fonte de oportunidades para as instituições de ensino superior, em especial a pós-graduação:

[...] uma formação complementar básica sobre empreendedorismo e inovação certamente preparará nossos estudantes de pós-graduação para o acesso ao mercado, para a abertura de novas empresas, e para a condução de pesquisas com uma visão diferenciada de mercado.

\section{Inovação}

Um dos principais (e seminais) autores do campo da inovação, Schumpeter (1986, p. 93) afirmava que "no peito de quem deseja fazer algo novo, as forças do hábito se levantam e testemunham contra o projeto em embrião". Em outras palavras, inovar é sempre desafiador.

A pesquisa básica ou fundamental, consideram Balconi, Brusoni e Orsenigo (2010), é a principal fonte de inovação; ou seja, a fim de inovar e chegar a novos produtos, é necessário que empresas dediquem recursos para pesquisa e desenvolvimento (P\&D). Silva (2016) argumenta sobre uma inovação que está disponível fora dos limites da empresa, a inovação aberta, que consiste na utilização de recursos compartilhados interna ou externamente à empresa visando à melhora do uso da inovação. No mesmo contexto, Machado (2007) e Chen, Dultra-de-Lima e Martins (2012) consideram que a inovação é um tema estratégico na administração, por isso as esferas acadêmicas com estudos voltados para essa linha de pesquisa precisam adequar-se à nova modalidade de vantagem competitiva. 
Em relação às ações necessárias para propiciar inovação, Cruz et al. (2013, p. 4) enfatizam que é preciso destacar a função da P\&D “tornando este um fator fundamental e decisivo para um efetivo sucesso nas políticas de investimento de um país ou de uma determinada região, para uma consequente promoção da inovação e desenvolvimento local como um todo". O mesmo panorama é registrado por Ferreira, Thiago, Pascual e Santos (2014, p. 4), ao defenderem que "o processo de inovação é visto como uma mola propulsora do desenvolvimento, sobretudo industrial e comercial, para toda e qualquer nação".

Desenvolvimento local se reflete em produtos e serviços adequados, incluindo um poder público com capacidade, empresas a atender à demanda de inovação e, não menos importante, a população dessa região. São esses atores que podem influenciar positivamente o sucesso da inovação, e a construção do conhecimento aplicado no processo do produto ou serviço é parte disso. Tomaél (2007) ressalta que quando a gestão do conhecimento é corretamente aplicada, com partilha de experiências e práticas, pode resultar em um desenvolvimento regional, além de enriquecer o ambiente sociocultural.

Balconi, Brusoni e Orsenigo (2010) enfatizam que o investimento em pesquisa é fundamental e que em algum momento do futuro ele trará não apenas novas invenções e tecnologias, como também, possível rendimento. Para esses autores, quem define as estratégias de inovação nas corporações mundiais são os líderes, com parceiros e outros interessados em lucrar sempre mais, já que para eles inovação é sinônimo de altos rendimentos.

Países desenvolvidos e em desenvolvimento perceberam a necessidade em organizar a busca por desenvolvimento econômico e por estratégias em inovação, razão por que foi criada, em 1961, a Organização para Cooperação e Desenvolvimento Econômico (OCDE). Com o estabelecimento desse órgão, houve melhoria na valorização dos estudos sobre Ciência e Tecnologia (C\&T), visto que ela é reconhecida como um órgão adequado de estratégia para o desenvolvimento econômico regional. Aliás, essa é uma das principais atividades da OCDE, a saber, buscar coerência entre P\&D e crescimento econômico (MANUAL DE OSLO, 2005).

Outro ponto ligado ao crescimento econômico é o crescimento regional. Tal como apontam Siqueira (2015) e Rocha e Vieira (2016), 
um importante contribuinte para esse desenvolvimento é a indústria, visto que possui a capacidade de progresso técnico, além de aprofundamento da divisão social do trabalho, causando uma estrutura produtiva diferenciada, além de ocupações de qualidade.

\section{Relação entre Educação e Inovação}

Uma vez que o Manual de Oslo (2005, p. 100) identifica que "as decisões sobre usar e trocar os conhecimentos existentes e como obter novos conhecimentos são fundamentais para a operação das organizações", é possível compreender que conceitos referentes à educação e à inovação tendem a caminhar juntos, tanto para o desenvolvimento das empresas quanto das instituições de ensino.

No caso específico das universidades, Castanho e Castanho (2005) e Falcão (2009) acreditam que é nelas que ocorre, da melhor maneira, o processo de ensino/aprendizagem; essa instância é uma divulgadora de conhecimento e proprietária de forte acervo cultural da humanidade. Outro trecho do Manual de Oslo (2005) contempla tal cenário:

A pesquisa e o desenvolvimento experimental (P\&D) compreendem o trabalho criativo realizado de forma sistemática com o objetivo de aumentar o estoque de conhecimentos, incluindo os conhecimentos do homem, da cultura e da sociedade, e o uso desse estoque de conhecimentos para antever novas aplicações (MANUAL DE OSLO, 2005, p. 105).

Pimenta e Anastasiou (2002, p. 64) identificam a educação como "um processo natural que ocorre na sociedade humana pela ação de seus agentes como um todo". Assim, constata-se relação entre educar e inovar. O clássico texto de Schumpeter (1986) aponta que inovar traz desenvolvimento e evolução para um país, pois existe um consenso de que educação e inovação constituem uma estrada longa e sinuosa que conduz ao desenvolvimento social e econômico. Luz e Santos (2007, p. 158) aprofundam um pouco mais a reflexão quando identificam que:

[...] empresas que desenvolvem produtos e serviços de alta tecnologia dependem e necessitam de uma estreita relação com as universidades e os centros de pesquisas. Estes centros atuam como fonte de suprimento de pessoal qualificado em programas de graduação e pós-graduação. 
Depreende-se, desse modo, que o aperfeiçoamento de recursos humanos pode significar um desenvolvimento econômico, social e regional para o país que segue essa diretriz. Segundo Lamenza, Pereira e Santos (2012, p. 859), “o termo inovação representa, em geral, um aumento de produtividade e desenvolvimento de mercados". No entanto, no Brasil, o investimento em educação e inovação tem sido escasso, o que acaba sendo um obstáculo para garantir tal desenvolvimento, afinal, são necessários recursos financeiros para suprir as demandas de investimento em educação. Castanho e Castanho (2005, p. 21) também fazem um alerta: “[...] uma das consequências das mudanças ocorridas no mundo do trabalho para o cotidiano da sala de aula universitária é a diminuição do investimento - e a decorrente perda de qualidade".

As instituições de ensino superior não estão alheias a esse contexto e, como principais fornecedoras de capital intelectual para o mercado, buscam por um currículo adequado e que atenda às exigências da legislação, das empresas e das outras instituições. Por isso, o caminho escolhido por este estudo para investigar parte das ações dos programas de pós-graduação (stricto sensu) foi a interpelação junto aos gestores dos programas.

\section{Procedimentos Metodológicos}

Para esta pesquisa, assumiu-se uma abordagem qualitativa, de modo a, segundo a perspectiva dos participantes, "adentrar no mundo dos significados" (GODOI; BANDEIRA-DE-MELLO; SILVA, 2010, p. 78). Para a coleta dos dados, foram realizadas entrevistas em profundidade, ancoradas em roteiro semiestruturado. Participaram das entrevistas seis gestores de programas de pós-graduação, preservando-se, para a elaboração deste artigo, seu anonimato.

A área de conhecimento explorada neste artigo é a de Ciências Sociais Aplicadas, área que contempla os cursos de Administração, Comunicação Social, Planejamento e Gestão do Território e Políticas Públicas.

As ciências sociais aplicadas constituem uma área do conhecimento e de atuação profissional multivalente, cuja formação conjuga o domínio de várias disciplinas, entre as quais se situam a administração e as 
ciências contábeis, que vêm adquirindo crescente importância no contexto da sociedade (DIEHL; TATIM, 2004, p. 36-37).

Os participantes pertencem às seguintes instituições de ensino, escolhidas porque possuem cursos de mestrado e doutorado na área de Ciências Sociais Aplicadas na região selecionada: Universidade Metodista de São Paulo (UMESP); Universidade Municipal de São Caetano do Sul (USCS); Universidade Federal do ABC (UFABC); e Centro Universitário da Fundação Educacional Inaciana (FEI). Na análise das entrevistas, eles serão destacados no texto pelo termo "ENTREVISTADO", acompanhado de número para a especificação do participante, sem relacioná-lo à instituição, de modo a evitar que o respondente seja identificado a partir de seu vínculo institucional. As entrevistas foram realizadas entre 27 de abril e 13 de maio de 2016, no local de trabalho de cada participante, levando, em média, cerca de 1 hora e 15 minutos. As especificações das unidades aos quais os gestores pertencem constam no quadro 1 .

\section{Quadro 1 - Cursos nas áreas de Ciências Sociais Aplicadas}

\begin{tabular}{|l|l|}
\hline Instituição de Ensino Superior & Curso - Níveis \\
\hline $\begin{array}{l}\text { Centro Universitário da Fundação } \\
\text { Educacional Inaciana (FEI) }\end{array}$ & $\begin{array}{l}\text { Administração - Mestrado } \\
\text { e Doutorado }\end{array}$ \\
\hline $\begin{array}{l}\text { Universidade Metodista de São } \\
\text { Paulo (UMESP) }\end{array}$ & Administração - Mestrado \\
\cline { 2 - 2 } & $\begin{array}{l}\text { Comunicação Social - Mestrado e } \\
\text { Doutorado }\end{array}$ \\
\hline $\begin{array}{l}\text { Universidade Municipal de São } \\
\text { Caetano do Sul (USCS) }\end{array}$ & $\begin{array}{l}\text { Administração - Mestrado } \\
\text { e Doutorado }\end{array}$ \\
\cline { 2 - 2 } & Comunicação - Mestrado ${ }^{*}$ ) \\
\hline \multirow{2}{*}{$\begin{array}{l}\text { Universidade Federal do ABC } \\
\text { (UFABC) }\end{array}$} & $\begin{array}{l}\text { Planejamento e Gestão do } \\
\text { Território - Mestrado e Doutorado }\end{array}$ \\
\cline { 2 - 2 } & Políticas Públicas - Mestrado \\
\hline
\end{tabular}

Fonte: CAPES (2015).

* Pr ter assumido a coordenação dias antes da entrevista, o gestor preferiu não participar da pesquisa. 
Para tratamento dos dados, buscou-se proceder a partir do que recomenda Godoy (1995, p. 23), em relação à análise de conteúdo, conforme as falas dos entrevistados: "um instrumental metodológico que se pode aplicar a discursos diversos e a todas as formas de comunicação". Bardin (2011), por sua vez, defende que a análise de conteúdo "é indicada para trabalhos com características qualitativas, já que enriquece a tentativa exploratória, além de aumentar a propensão para a descoberta" (BARDIN, 2011, p. 35).

Especificamente em relação aos procedimentos para a análise, seguiu-se a recomendação de Franco (2012), para o estabelecimento de categorias criadas a priori. Neste caso, "as categorias e seus respectivos indicadores são predeterminados em função da busca a uma resposta específica do investigador" (FRANCO, 2012). As categorias, elencadas a partir do campo conceitual assumido, foram as seguintes: "posição temática da inovação na pós-graduação"; e "colaboração entre governo, empresas e instituições de ensino".

\section{ANÁLISE DOS RESULTADOS}

\section{Posição Temática da Inovação na Pós-Graduação}

Os entrevistados assumem ser importante a divulgação do tema no ensino superior, especialmente nos programas de pós-graduação. No entanto, alguns acreditam que estudar inovação não está associado a uma disciplina específica, mas sim algo que faça parte de todas.

Nós temos hoje uma disciplina, que é obrigatória, que é gestão da inovação, que todos os alunos fazem. O que nós estamos repensando agora é tirar essa disciplina como gestão da inovação, e pegar esse conteúdo, e colocar dentro das disciplinas das áreas. Então, sair de uma disciplina única, ou que vai focar, mas tentar permear justamente a inovação, em todo o contexto, de todas as disciplinas que a gente está trabalhando. (ENTREVISTADO 1)

Mas o conceito de inovação acaba permeando as atividades, né? Todas... todos os níveis de atuação de um programa de pós-graduação, desde a parte pedagógica, a parte de gestão, a parte de relacionamento com as agências de fomento e também as próprias diretrizes, que são 
elaboradas para a área, né? Agora, a gente não fala, necessariamente, "olha, vamos discutir a inovação", né? Ela acaba sendo uma prática, uma consequência das discussões que são feitas para a gente poder avançar na área, porque o intuito é sempre você avançar. (ENTREVISTADO 2)

Para o Entrevistado 1, a sociedade traz novos conceitos de desenvolvimento, por isso considera importante pensar em produtos e processos novos. O Entrevistado 2, por sua vez, identifica a inovação como uma prática para evoluir em seu programa de pós-graduação, "porque o intuito é sempre você avançar", defende.

Então, esse é um processo de aprendizado que gera um profissional que vai ser inovador, ou ele vai trabalhar com pessoas que vão inovar no futuro. Eu acho que a gente faz parte de uma cadeia, essa cadeia de inovação. Para inovar, você sabe, você tem que ter o conhecimento, tem que ter a infraestrutura, tem que ter a boa ideia e tem que ter alguém que faça! Porque inovação é: uma boa ideia colocada em prática. (ENTREVISTADO 1)

Os entrevistados acreditam que pesquisa séria e de boa qualidade pode levar a uma inovação, mesmo que esta não tenha sido destacada em seus programas de pós-graduação. Cruz et al. (2013) apontam a pesquisa como algo fundamental para políticas de investimento de uma região, tendo como consequências a inovação e o desenvolvimento local. O Entrevistado 2 complementa o entendimento exposto pelo colega, ao afirmar que conhecimento gera conhecimento, e esse é um item imensurável.

Na verdade, é evidente que a pesquisa é a base da geração da inovação na nossa sociedade. [...] Mas a maior parte da estrutura do mestrado é a pesquisa aplicada, para tentarmos descobrir o que está dando certo na sociedade. Então, a princípio, a inovação vem. (ENTREVISTADO 5)

Você leva seu conhecimento para lá e você traz também o conhecimento. Então existe uma coisa que é imensurável. A gente não consegue mensurar! É imaterial, mas que você vai se apropriando, a partir daquela "olha, foi ótima aquela professora", não é? (ENTREVISTADO 2) 
Discutir inovação, conforme analisa o Entrevistado 3, tem sido uma temática atual e relevante; ele relata até que a CAPES, preocupada com isso, trouxe informações acerca do assunto em uma de suas revistas. Autores como Bryan, Benito e Suarez (2011, p. 77) afirmam que informação e conhecimento vêm desempenhando um papel importante na sociedade, onde se vive a era do conhecimento e da informação. O depoimento do Entrevistado 4 leva em consideração que a inovação é um tema transversal, ou seja, compreende como importante e urgente conhecê-lo, tanto nos programas de pós-graduação como no ensino superior como um todo.

Você vê que quando a CAPES lançou recentemente uma revista, sua revista de pós-graduação, dedicada à inovação, ela, a inovação, se tornou um tema preponderante na pós-graduação brasileira como um todo, pelo menos na visão das políticas públicas. (ENTREVISTADO 3)

[...] nos programas como um todo, tanto no stricto, quanto no lato sensu, na graduação, eu entendo que inovação é um tema transversal, até. Precisaria ser tratado como algo desejável em todas as áreas do conhecimento para que você possa galgar um desenvolvimento melhor para seu país... (ENTREVISTADO 4)

A inovação pode até não ser um assunto tratado de forma exclusiva, mas está sempre permeando as atitudes e decisões do dia a dia da sociedade e das instituições em geral. Em alguns casos, os entrevistados 5 e 6 entendem que o próprio estilo de estudos desenvolvidos em programas de pós-graduação já constitui uma espécie de inovação; entretanto, não vê necessidade de uma abordagem exclusiva, seja de forma individual, como uma disciplina, seja pulverizada nos cursos, como explanado por outros entrevistados.

O papel da inovação é... bem, não sei se quando a gente pensa um programa, a gente pensa necessariamente em inovação em si, né? Começa, a princípio, no que já existe, né? Inclusive na própria universidade, então - que por sua natureza já é bastante inovadora, né? (ENTREVISTADO 5) 
Ah... eu fico me perguntando o que é inovação. [...] então, por isso que a pergunta: o que é inovação? [...] então, acho que por aí a gente está inovando. Então, na hora que a gente traz, no nosso programa, arquitetos urbanistas, economistas, sociólogos, demógrafos e cientistas políticos, a gente está buscando trabalhar a multidisciplinaridade que deve ser, o território deve ser olhado. (ENTREVISTADO 6)

Alguns participantes da pesquisa entendem que a inovação deve ser um assunto distribuído entre as ementas disciplinares e a própria estrutura do programa de pós-graduação. Já o Entrevistado 3 acredita que a inovação necessita de uma disciplina estruturada. Em sua avaliação, o assunto possui muitos níveis que precisariam ser explorados. Para o Entrevistado 2, um dos papéis dos programas de pós-graduação é ser interlocutor entre a universidade e a sociedade, criando assim espaços para essa interação.

Na minha opinião, estudar inovação, pede a estruturação de uma disciplina, o que não exclui você estudar inovação em outras disciplinas, mas você precisa dedicar uma carga para isso porque ela; tem muita gente falando hoje sobre inovação, mas não trata a inovação em todas as suas... como eu vou dizer, em todos os níveis que ela precisa ser abordada. (ENTREVISTADO 3)

Do que seja, do que faz um programa de pós-graduação, quais são as atividades. Eu acho que talvez, uma ação inovadora seria criar novos espaços de interlocução entre as diversas instâncias nas universidades, e também com as comunidades, com a sociedade de maneira geral, para que elas pudessem saber o que faz e cobrar. Porque também essa cobrança, a gente tem uma cobrança muito grande dos órgãos que controlam e fiscalizam, né? Mas a sociedade, como a sociedade está muito afastada do conhecimento científico, há muito pouca cobrança da sociedade. (ENTREVISTADO 2)

O Entrevistado 3 faz uma crítica quanto ao formato disponível de programas de pós-graduação, no Brasil, em que a criatividade do aluno é deixada de lado em prol das necessidades da instituição de ensino: 
[...] no stricto sensu, a relação de poder ainda é medieval, então como você tem poucas vagas, muita gente querendo, para um professor te aceitar como orientador, é um processo medieval. Aí você tem que se encaixar na linha de pesquisa dele, você tem que caminhar do jeito que ele quer, você não pode pesquisar, às vezes, uma coisa muito inovadora, porque ele não domina aquele tema, aí você fica numa dependência. O que eu mais vejo no Brasil afora são mestrandos e doutorandos angustiados. Que gostariam até de pesquisar coisas mais inovadoras, talvez usando, inclusive, métodos mais inovadores, mas que acabam tendo que se adaptar, porque senão não conseguem pegar o seu título. (ENTREVISTADO 3)

O Entrevistado 3 acredita na existência de uma dependência dos alunos de stricto sensu em relação aos seus orientadores, ao passo que o Entrevistado 4 vê os cursos de mestrado e doutorado como precursores de novos pesquisadores. No entanto, o Entrevistado 3 percebe que as universidades que possuem cursos na área de stricto sensu precisam adaptar-se a uma demanda criada pela própria tecnologia, como a Internet. A adequação do capital humano às adversidades do mercado é uma associação saudável quando o produto final a ser alcançado é o desenvolvimento científico e tecnológico, conforme sinaliza o PNPG (BRASIL, 2010).

Quando você começa a entender qual é a função do mestrado, e que a dissertação, ela tem que ser proveniente de uma pesquisa, aí, portanto, você é um pesquisador, aí muda sua visão. (ENTREVISTADO 4)

Na pós-graduação, falando não só na pós-graduação, mas falando em uma universidade, que tenha stricto sensu, a rigor, a universidade tem que mudar o seu, tem que mudar completamente o que faz, porque a tarefa de difusão do saber, ela está muito afetada pela presença da internet. Então assim, o conhecimento, a informação, está disponível em algum lugar. (ENTREVISTADO 3)

A reflexão sobre os programas de pós-graduação no Brasil relatada pelos entrevistados aponta que um programa precisa preocupar-se com a sociedade e com o seu crescimento; e a forma 
para que isso aconteça é por meio da pesquisa. A CAPES ressalta a importância da produção científica como um contribuinte significativo para o desenvolvimento nacional. O Entrevistado 5 ressalta a relevância de avançar no assunto científico, mas esclarece que há uma cobrança, sem especificar a sua origem. No entanto, ele vê que esta é a função dos programas de pós-graduação: criar uma excelência acadêmica.

Então, mesmo que a gente tenha, a gente está tendo uma estrutura acadêmica, também, que prima pela parte da consistência científicotécnica, científico-acadêmica e a gente é muito cobrado para isso, mas a gente está sempre tentando criar um certo equilíbrio entre avanço e, como dizer? Em excelência em ciência acadêmica. E ao mesmo tempo, estar fiel à ideia da responsabilidade social. (ENTREVISTADO 5)

Na fala dos entrevistados, nota-se que entendem existir formas de inovação quando buscam interagir com outras áreas de atuação fora do seu contexto habitual de estudo, tal qual preconiza o Manual de Oslo (2005): a exploração de conhecimento e as medidas de inovação são fundamentais para o desenvolvimento econômico e social das nações.

\section{Colaboração entre Governo, Empresas e Instituições de Ensino}

Um dos assuntos mais discutidos durante as entrevistas foi a falta de apoio financeiro à educação no Brasil. Ao se mencionar a inovação, os entrevistados já começaram as respostas da seguinte maneira: "Pergunta difícil!" Não houve unanimidade quanto à ausência de recursos, pois acreditam na existência do dinheiro e apontam a desorganização econômica como causadora de recursos escassos e/ou mal distribuídos. Autores como Pinheiro et al. (2014) mencionam a dificuldade que o empreendedor possui para ter acesso às fontes de financiamento do governo e de como esse obstáculo enfraquece o desenvolvimento nacional.

Eu imagino assim: é lógico que mais dinheiro pode fomentar mais. Mas eu acho que a gente tem que usar bem o dinheiro. O problema do nosso país, não é falta de dinheiro, é jogar dinheiro onde não 
deve. Desperdiça, rouba, leva, faz, tal. É usar mal o dinheiro. (ENTREVISTADO 1)

Os entrevistados 3 e 5 apontam a crise política e a falta de contribuição política para o desenvolvimento de pesquisas de peso, em que é possível criar uma expectativa de inovação realmente impactante para o desenvolvimento do mercado nacional. Segundo o Entrevistado 3, ainda estamos presos a commodities, ao passo que o Entrevistado 5 menciona que as ciências sociais não possuem pesquisas com relevância, na visão de alguns políticos.

E você vê a crise do Brasil, hoje. Nós temos uma crise política. [...] qual é a causa? A causa é que nós temos uma matriz econômica não inovadora. Nós temos uma matriz econômica baseada em commodities, de exportação de commodities. Nós tivemos uma crise mundial de commodities, caiu a nossa venda, ao cair a nossa venda, não tem arrecadação. E aí começa tudo. (ENTREVISTADO 3)

Parece que a sociedade ainda tem uma visão meio cética a respeito disso. O exemplo é a afirmação do nosso governador, recentemente; quando ele estava na FAPESP, reclamando que estava gastando um dinheirão para financiar ciências sociais, que não são de nenhuma utilidade para a sociedade. Como sociologia, por exemplo. Enquanto não existem recursos para investir, para combater o vírus da ZICA, o ZICA-vírus, coisas assim, né? Uma pessoa que se mostrou nesse caso, totalmente despreparada, porque ele não entende do que fala. (ENTREVISTADO 5)

A inovação, segundo Bryan, Benito e Suarez (2011), depende de vontade política e de uma consciência crítica de mudança de rumo. Colaborações externas para com as universidades, de acordo com o Entrevistado 4, ajudam bastante no desenvolvimento tanto do aluno como também dos professores. O governo e as empresas, trabalhando com as instituições de ensino, podem e devem contribuir com a inovação, como dito por Etzkowitz e Leydesdorff (2000). Pereira et al. (2015) destacam a importância de relacioná-la com o desenvolvimento econômico. Sendo assim, os autores citados e o 
Entrevistado 4, destacado a seguir, concordam que, para haver inovação, é necessária uma colaboração externa, seja da universidade, seja do governo, seja da empresa.

[...] aqui no nosso programa, stricto sensu, particularmente, nós fazemos algumas visitas. Nós fazemos visitas técnicas em algumas empresas, fazemos visitas técnicas na incubadora da USP, ou em outras, fazemos visitas técnicas em órgãos governamentais, em que a gente possa tirar de lá algumas ideias, algumas conversas, algumas entrevistas, né? Tem muitas coisas que nós fazemos. Cada ação dessa, em que a gente sai para fora dos muros da instituição de ensino, ela agrega muito valor. Porque você sabe que aquilo que você lê, você assimila, mas poderá um dia até esquecer, mas o que você viu, o que você foi lá e viu "in loco", é muito difícil de você esquecer. Então uma visita técnica ainda é muito bem-vinda, ainda no stricto sensu. (ENTREVISTADO 4)

Ainda sobre a questão de parcerias externas, o Entrevistado 4 continua:

As pessoas lá da empresa têm que querer nos receber, tem lá um trâmite burocrático para isso. Então não é muito fácil de isso ocorrer, mas é muito desejado, né? Nós fomos, por exemplo: no ano passado, nós fomos para a Braskem. Fizemos lá uma visita à Braskem, recebemos palestras, visitamos e foi muito legal, porque assim, nós fomos lá para ouvir falar de sustentabilidade e políticas públicas, essas coisas. (ENTREVISTADO 4)

O Entrevistado 4 foi um dos poucos que ainda apresentaram certa facilidade nessa aproximação. No entanto, no decorrer da entrevista, foi possível perceber que isso costuma acontecer com a iniciativa da instituição de ensino que, buscando conhecimento além da sala de aula, não desiste dessa troca de experiências e informações. O incentivo ao relacionamento empresa/universidade, a interação e a aprendizagem, como dito por Falcão (2009), fomentam a inovação e a gestão de conhecimento.

Já o Entrevistado 3 não acredita que exista um diálogo, como ele mesmo disse no seu relato: “Ouso dizer que há uma minoria que 
mantém diálogo com empresa". E ainda complementa ao apontar que a inovação também é um assunto pouco discutido nos programas de pós-graduação, pelo menos dentro da complexidade e dos níveis que deveriam.

Na pós-graduação stricto sensu brasileira, eu ouso dizer que há uma minoria que mantém diálogo com empresa. Um diálogo realmente efetivo. Produtivo com a empresa, um diálogo sistemático com empresas, sabe? Muito poucas. E eu creio que a inovação na pós-graduação stricto sensu também é em pouquíssimos programas que ela ocupa um lugar, digamos, de destaque na concepção e na prática do problema. Eu acho que as pessoas já estão falando de inovação. São poucas pessoas que realmente entendem de inovação, dentro dessa complexidade que eu te mostrei, de níveis e tudo, e aí novamente, é um problema que não é só da pós-graduação, é um problema desse contexto, de como as nossas instituições de ensino superior estão organizadas, de como que o financiamento das ciências está organizado, da nossa pouca capacidade operacional, por exemplo, para lidar com patentes, para lidar com, transformar inovação em um produto comercialmente viável. Então assim, eu creio que nós estamos num momento de nascedouro do assunto. (ENTREVISTADO 3)

O Entrevistado 5 avalia como importante o diálogo entre universidade e empresa, mas fala da dificuldade que ainda existe para se "romper com as fronteiras entre a academia e a prática". Ele acredita que essa fronteira possa ser rompida quando as pessoas que estão na academia, na condição de alunos de mestrado ou doutorado, trabalharem em empresas e levarem essa necessidade de troca de conhecimento.

Nesse processo, de encorajar, talvez, de analisar, avaliar e depois de levar esse conhecimento para a sociedade, através de bancos de referências; de boas práticas que podem ser analisadas, avaliadas. Claro! Acho que tem sempre um pouco, ainda uma dificuldade, de romper com as fronteiras entre a academia e a prática. Acredito que a gente, à medida que a gente está formando mestrandos, que estão atuando. Atuando nas prefeituras, atuando nos municípios, etc. Você, já através 
disso, você contribui para que as pessoas que estão ocupando cargos, que estão ocupando funções dentro da administração pública, de eles terem um posicionamento, uma abordagem mais... primeiramente mais crítica ao que eles estão fazendo, ao que eles estão questionando e repensando suas estratégias. (ENTREVISTADO 5)

Mesmo com dificuldades para que essa interação empresa/ universidade ocorra, alguns coordenadores entendem que vale a pena o esforço, já que se trata de uma troca. "A troca é essencial; ela é inovadora" (ENTREVISTADO 2).

Então, a gente tem essa interação com as empresas, mas não é uma coisa obrigatória e não é com todos os professores. Às vezes a nossa interação com as empresas é muito mais para buscar dados. A gente tem muito aluno de empresa aqui, de banco, e tudo mais, né? Então a gente tem essa interação aqui com as empresas, mas não é o nosso foco criar essa ponte, não é o nosso trabalho. A gente precisa criar o conhecimento. (ENTREVISTADO 1)

O Entrevistado 6, em consonância com os relatos já mencionados, identifica que mesmo com o aumento do número de bolsas disponibilizadas pelo governo, a quantidade de candidatos que precisam delas para poder estudar num curso de mestrado ou doutorado aumentou, em proporção, mais do que a oferta. Como a própria CAPES estipula no PNPG (BRASIL, 2010, v. 1, p. 269), “o pilar básico do desenvolvimento científico e tecnológico de qualquer sociedade está na formação de pesquisadores e cientistas".

Então! Então, a captação de recurso é muito difícil. Nós temos observado nos últimos anos, uma gigantesca quantidade de candidato, que precisa de bolsa. Assim, a grande maioria no último processo seletivo era gente que não trabalhava, ou pelo menos declarava que não trabalhava. Então eu acho que recurso de bolsa, recurso de pesquisa, é fundamental. Para sobrevivência, que está muito difícil. Isso é uma dificuldade. (ENTREVISTADO 6)

O Entrevistado 4 aponta que até existem incentivos, por alguns órgãos de fomento, para pesquisa em inovação: 
Sinceramente eu não sei se há políticas públicas de estímulo monetário, financeiro para isso. Se há fomento para essas pesquisas. Eu sei que tem porque os órgãos de fomento, como CAPES, CNPQ e FAPESP. Eles incentivam as pesquisas em inovação, mas dentro da área de Administração, especificamente, poderia ser melhor enfatizado. Agora eu sei, por exemplo, que tem programas específicos em que a área de concentração é a inovação. (ENTREVISTADO 4)

Ainda, segundo o entrevistado citado, escrever as regras é mais fácil do que aplicá-las. Elas fazem parte, em sua maioria, do novo PNPG 2011-2020, editado pela CAPES e que tem como “objetivo definir novas diretrizes, estratégias e metas para dar continuidade e avançar nas propostas para a política de pós-graduação e pesquisa no Brasil" (BRASIL, 2010, p. 2). No relato do Entrevistado 2, há menção de iniciativa voltada à comunidade externa, em busca de inserção social do programa de pós-graduação, quando destacou que iniciativas dessa natureza não devem ser limitadas à sala de aula ou à opinião de professores:

Esse foi um formato. Agora a gente está fazendo outros, com temáticas que sejam abrangentes, que sejam temáticas sociais. Nós fizemos um, na semana passada sobre ideologia de gênero. Essa discussão o Plano Nacional de Educação, e como essas questões de gênero, elas deixaram de ser discutidas, eliminadas do Plano Nacional de Educação. E quais são as repercussões, quais são as relações que isso tem com a mídia, com a política e com a religião, né? Então a gente, abriu à comunidade externa essa discussão, né? A proposta agora é a gente fazer um com educação e depois fazer um com administração. Então, esse é um exemplo de ação que você ajuda a formar cidadãos que não estão ligados ao programa. (ENTREVISTADO 2)

E assim, mesmo tendo sido uma "pergunta difícil", como mencionado pelos participantes, as opiniões sobre o assunto indicaram que as políticas públicas para a inovação em pesquisa e na pós-graduação ainda carecem de investimento e reflexão por parte dos órgãos governamentais. 


\section{CONSIDERAÇõES FINAIS}

Em termos teóricos, este trabalho demonstrou existir um relacionamento entre estudo sobre inovação com o currículo acadêmico, além dos apontamentos a respeito de inovação no ensino superior identificados nos documentos oficiais, como o PNPG 2011-2020. Aliás, o próprio documento preconiza uma pós-graduação mais preocupada com a dinâmica de transformar alunos dos cursos de mestrado e doutorado em pesquisadores de ponta. Além disso, um dos assuntos amplamente tratados no seu conteúdo está relacionado à inovação e sua prática dentro dos programas de pós-graduação.

Em termos práticos, com o auxílio dos depoimentos dos entrevistados, identificou-se que a inovação não deve ser apenas uma disciplina, mas fazer parte de toda a estrutura dos programas de pós-graduação.

A análise demonstrou que, para haver progresso e inovação, é preciso derrubar algumas barreiras, como a de colocar o estudo sobre a inovação dentro de disciplinas e dos programas. Mesmo havendo um redesenho de trabalhos constantes, conforme assinalado pelos entrevistados, estudar inovação não é tão simples para programas que não possuem esse foco, posto que a inovação é tema transversal. Os entrevistados apontaram que inovação traz avanço e que o seu papel no mercado e nas instituições de ensino é o de levar desenvolvimento. Alguns coordenadores sentem que é sua obrigação transformar os alunos e pesquisadores (prioritariamente), em agentes da inovação. No entanto, não fazem referência a uma disciplina, mas a atividades, troca de conhecimentos e de habilidades que os programas deveriam promover entre os seus alunos e professores.

Também merece destaque, pelo cenário descrito pelos respondentes, o fato de o Brasil investir pouco em ciência e tecnologia, acarretando em menor qualidade no ensino, e por conseguinte, no desenvolvimento de pesquisas; ou seja, investir precariamente em pesquisa e desenvolvimento tem sido uma prática desestimulante no sistema de ensino ligado aos programas de pós-graduação brasileiros. É necessário um interesse maior por parte do Estado para que se possa aumentar a capacidade do Brasil em pesquisar, desenvolver, publicar e - o mais importante - trazer resultados abrangentes e esperados pela sociedade por intermédio da pesquisa.

Esta pesquisa restringiu-se às universidades localizadas no $A B C$ paulista. Além dessa limitação, outro ponto estabelecido foi de que 
seriam investigados os cursos na área de Ciências Sociais Aplicadas, ou seja, a pesquisa não teve abrangência nacional e não ouviu a opinião de todos os coordenadores do Brasil, nem de todos os cursos. Dadas as limitações, recomenda-se realizar estudos em outras áreas de conhecimento e em outras regiões do Brasil. Como se trata de assunto abrangente, a investigação quanto à opinião de pesquisadores especializados na área de inovação pode ser um caminho promissor.

\section{REFERÊNCIAS}

BALCONI, M.; BRUSONI, S.; ORSENIGO, L. In defence of the linear model: an essay. Research Policy, v. 39 (1), p. 1-13, 2010.

BARDIN, L. Análise de conteúdo. Lisboa: Edições 70, 2011.

BRASIL. Lei n. 9.394, de 20 de dezembro de 1996. Diário Oficial da União, Poder Legislativo, Brasília, DF, 1996.

BRASIL. Ministério da Educação. Coordenação de Aperfeiçoamento de Pessoal de Nível Superior - Plano Nacional de Pós-Graduação - PNPG 2011-2020. Brasília, DF: CAPES, v. 1, 2010.

BRYAN, N. A. P.; BENITO, A. E.; SUÁREZ, H. H. (Org.). Educação e conhecimento para um futuro sustentável. Campinas: Alínea, 2011.

CAPES. Coordenação de Aperfeiçoamento de Pessoal de Nível Superior. Plataforma Sucupira, 2015.

CASTANHO, S.; CASTANHO, M. E. (Orgs.). Temas e textos em metodologia do ensino superior, 7. ed. Campinas: Papirus, 2005.

CHEN, Y. T.; DULTRA-DE-LIMA, R. G.; MARTINS, V. F. Processo de inovação: análise sob a ótica dos elementos organizacionais - revisão literária estruturada e implicações para pesquisas futuras. Revista Organizações em Contexto, v. 8, n. 16, p. 91-129, 2012.

CRUZ, F. G.; CRUZ, A. G.; COSTA, L. V.; CORONEL, D. A. Tríplice hélice na região da campanha: um ensaio teórico como fator estratégico de inovação e desenvolvimento. Revista FACEF Desenvolvimento e Gestão, v. 16, n. 3, p. 281-300, 2013.

DEMO, P. Educar pela pesquisa, 5. ed. Campinas: Autores Associados, 2002.

DIEHL, A. A.; TATIM, D. C. Pesquisa em Ciências Sociais Aplicadas: métodos e técnicas. São Paulo: Prentice Hall, 2004.

ETZKOWITZ, H.; LEYDESDORFF, L. The dynamics of innovation: from national systems and "mode 2 " to a triple helix of university - industry - government relations. Research Policy, v. 29, n. 2, p. 109-123, 2000.

FALCÃO, J. P. C. Influências do compartilhamento da informação e do conhecimento no processo de inovação em empresas de base tecnológica. Perspectivas em Ciência da Informação, v. 15, n. 1, p. 318, 2009.

FERREIRA, H. M. G.; THIAGO, F.; PASCUAL, J. V. I.; SANTOS, I. C. Gestão da Inovação: Uma análise dos indicadores de inovação da América Latina. In: Encontro Internacional sobre 
Gestão Empresarial e Meio Ambiente, 16, São Paulo, 2014. Anais... São Paulo: FEAUSP, 2014. FRANCO, M. L. P. B. Análise de Conteúdo: série pesquisa v. 6, 4. ed. Brasília: Liber Livros, 2012, 96 p.

GODOI, C. K.; BANDEIRA-DE-MELLO, R.; SILVA, A. B. Pesquisa qualitativa em estudos organizacionais: paradigmas, estratégias e métodos, 2. ed. São Paulo: Saraiva, 2010.

GODOY, A. S. Pesquisa qualitativa: tipos fundamentais. Revista de Administração de Empresas. São Paulo, v. 35, n. 3, p. 20-29, 1995.

LAMENZA, A.; PEREIRA, R. S.; SANTOS, I. C. Comercialização de créditos de carbono no Brasil: oportunidade de inovação nos negócios. Revista de Ciência e Administração, Fortaleza, v. 18, n. 2, 2012.

LUZ, M. S.; SANTOS, I. C. Ciência, tecnologia e pesquisa tecnológica: a luta por uma política nacional em C\&T. Revista Produção Online, v. 7, n. 7, p. 152-182, 2007.

MACHADO, D. D. P. N. Organizações inovadoras: estudo dos fatores que formam um ambiente inovador. Revista de Administração e Inovação, v. 4, n. 2, p. 5-28, 2007.

MANUAL DE OSLO. 3. ed. 2005. <http://www.mct.gov.br/. Acesso em: 26 maio 2017.

PEREIRA, R. S.; FRANCO, I.; SANTOS, I. C.; VIEIRA, A. M. Ensino de inovação na formação do administrador brasileiro: contribuições para gestores de curso. Administração, Ensino e Pesquisa, n. 1, p. 101-113, 2015.

PIMENTA, S. G.; ANASTASIOU, L. G. C. Docência no ensino superior. São Paulo: Cortez, 2002. PINHEIRO R. G.; SANTOS, I. C.; MAIA, C.; FERNANDES, B. A. O. F. A produção científica sobre inovação: análise de base Scielo no período de 2005 a 2012. Estudos Tecnológicos em Engenharia, n. 1, p. 36-48, 2014.

ROCHA, A. F. R.; VIEIRA, A. M. Aprendizagem Organizacional e Inovação de Produtos: estudo em Empresas de Base Tecnológica do Vale da Eletrônica (MG). Caderno Profissional de Administração da UNIMEP, v. 6, n. 1, p. 108-131, 2016.

SCHUMPETER, J. A. Teoria do desenvolvimento econômico: uma investigação sobre lucros, capital, crédito, juro e o ciclo econômico. São Paulo: Nova Cultural, 1986.

SILVA, S. B. A capacidade dinâmica de "Orquestração de Redes de Inovação" no Modelo de Inovação Aberta. Revista Alcance, v. 23, n. 1, p. 19-33, 2016.

SILVA, T. C.; BARDAGI, M. P. O aluno de pós-graduação stricto sensu no Brasil: revisão da literatura dos últimos 20 anos. Revista Brasileira de Pós-Graduação. Brasília, v. 12, n. 29, 2015.

SIQUEIRA, H. Novo desenvolvimentismo e dinâmica urbano-regional no Brasil (2004-2012).

Revista EURE - Revista de Estudios Urbano Regionales, v. 41, n. 122, p. 261-277, jan. 2015.

TOMAÉL, M. I. Redes Sociais, conhecimento e inovação localizada. Informação \& Informação, Londrina, v. 12, n. 1, ed. esp., 2007.

Recebido em: 23-9-2017

Aprovado em: 12-12-2017

Avaliado pelo sistema double blind review.

Editor: Elmo Tambosi Filho

Disponível em http://mjs.metodista.br/index.php/roc 